\title{
Pattern of Acute Asthma Seen in Children Emergency Department of the River State University Teaching Hospital Portharcourt Nigeria
}

\author{
Uchenna C. Onubogu* ${ }^{\circledR}$, Edith Owate \\ Rivers State University Teaching Hospital, Port Harcourt, Nigeria \\ Email: *utchayonubogu@yahoo.co.uk
}

How to cite this paper: Onubogu U.C., and Owate, E. (2019) Pattern of Acute Asthma Seen in Children Emergency Department of the River State University Teaching Hospital Portharcourt Nigeria. Open Journal of Respiratory Diseases, 9 , 101-111.

https://doi.org/10.4236/ojrd.2019.94009

Received: September 15, 2019

Accepted: October 11, 2019

Published: October 14, 2019

Copyright $\odot 2019$ by author(s) and Scientific Research Publishing Inc. This work is licensed under the Creative Commons Attribution International License (CC BY 4.0).

http://creativecommons.org/licenses/by/4.0/

\begin{abstract}
Acute exacerbations of asthma are one of the leading causes of emergency room visits and hospitalizations in children. Asthma exacerbations also demonstrate a seasonal pattern in which high rates can be seen at a particular season and knowledge of the seasonal pattern of asthma exacerbation in any locality can improve asthma management. Objective: To determine the prevalence, management outcome and seasonal pattern of emergency department visits for acute exacerbation of asthma. Methods: This was a retrospective review of the emergency department register of all asthma admissions in the Rivers State University Teaching Hospital, Portharcourt, Nigeria over a five year period from January 2014 to December 2018. Results: A total of 205 (2.9\%) asthma-related visits were recorded out of 7046 emergency room visits. The mean age of the patients was $6.1( \pm 4.2)$ yrs, with an M:F ratio of 1.97:1. The median length of hospital stay was $24 \mathrm{hrs}$. Children older than 11 yrs were more likely to be admitted for $>48 \mathrm{hrs}$ (OR 4.18, 95\% CI; 1.67, 10.39, $\mathrm{P} ; 0.003)$. Emergency department visits for asthma were more in the rainy season April-September 129 (63.9\%) with a peak in May. There is a significant variation in the seasonal pattern of emergency room asthma admission with age $(\mathrm{P}=0.018)$. Children $>3$ yrs have their highest admission rates in May while younger children experience two peaks in February and November. Conclusion: Asthma exacerbation is more in rainy season among children in Portharcourt although there is a variation in seasonal pattern of asthma exacerbation with age.
\end{abstract}

\section{Keywords}

Asthma Exacerbation, Emergency, Seasonal Variation, Children, Nigeria, Africa 


\section{Introduction}

Asthma exacerbations are acute or subacute episodes in which there is a progressive increase in asthma symptoms (cough, difficulty breathing, wheezing and chest tightness) such that urgent health care is usually required [1]. Acute exacerbations of asthma are one of the leading causes of emergency room visits and hospitalizations in children. It also leads to absence in school, reduced quality of life and constitutes a social and economic burden to the society [2].

In a national survey in the USA, the number of persons with at least one asthma attack within a 12 month period increased by $2.6 \%$ annually from 11 million persons in 2003 to 13.9 million persons in 2010. The prevalence rate in children was $5.2 \%$ to $5.5 \%$ from the national survey [3]. While in Nigeria acute asthma accounted for $6.5 \%$ of emergency room admissions [4].

Exacerbation of acute asthma can be triggered by allergens, respiratory tract infections, cold weather, stress and environmental pollutants [5] [6]. Asthma exacerbations also demonstrate a seasonal pattern in which high rates can be seen at a particular season. This pattern also varies for different geographic locations. In United Kingdom and USA peak asthma exacerbations have been reported to occur during early autumn/fall (September to November) which is associated with lots of winds and heavy rainfall which drive pollens and respiratory viruses, on the other hand the least presentation is during summer (June-August) [7]. In Australia the peak asthma admissions were seen in late February and November [8]. Besides a single-center study that was done in Enugu SE Nigeria, which recorded peak asthma admissions during the rainy season which is from May to June [4], there is limited data on the seasonal pattern of asthma exacerbations in Nigeria.

Knowledge of the seasonal pattern of asthma exacerbation in any locality would aid healthcare workers, patients and their caregivers in anticipating these seasonal spikes so that they can be proactive in their management of asthma by influencing pre-seasonal modifications to asthma treatment plans in order to improve asthma control and quality of life of these patients. In view of this, we set out to determine the prevalence, management outcome and seasonal pattern of emergency department visits for acute exacerbation of asthma.

\section{Method}

This study was a retrospective review of the hospital records of children who were admitted into the children emergency ward of Rivers State University Teaching Hospital (RSUTH), Port-Harcourt, Nigeria from January 2014 to December 2018. The Rivers state university teaching hospital is a tertiary hospital located in Portharcourt city, Nigeria. It is one of two tertiary hospitals serving a population of 5,198,716 people. The children emergency department which takes care of children aged $\leq 16$ years is open for 24 hours every day of the week and it treats an average of 1724 patients annually. All Children who present in the emergency ward are usually triaged by the nurse and seen by the paediatric resi- 
dents who work under a supervising consultant. All visits to the emergency room are recorded in a register. Acute asthma exacerbation was defined by presence of rhonchi with either of cough, difficulty breathing and chest pain that responds to use of short acting beta agonist (clinical demonstration of reversible bronchoconstriction) [1]. The treatment protocol for the hospital gives corticosteroids and short acting beta agonist for asthma exacerbation serious enough to be hospitalized, escalation of treatment requirements is according to GINA guideline [2]. Children who had sustained improvement of their symptoms, those whose bronchodilator treatment was at least $4 \mathrm{hrs}$ apart and those who had a care giver that could observe for symptom deterioration and the ability to continue home treatment plan were eligible to be discharged home. All children who are seen in emergency department and managed for acute exacerbation of asthma are discharged to the hospital's paediatric weekly asthma clinic to be followed up with a GINA guide line directed management plan [2]. Ethical clearance was sort from the hospital ethical committee. The emergency department register of all asthma admissions within the study period was reviewed and the following information was extracted: age, gender, diagnosis, date of admission/discharge, duration of stay, outcome and follow-up status.

Data collected was manually entered into Microsoft excel spreadsheet and analyzed using Epi Info 7 statistical software. The values were expressed using frequency tables, percentages, means, median, percentiles, bar chart and graph. Where relevant, results were reported in odds ratio and $95 \%$ confidence interval.

\section{Results}

A total of 7046 admissions were recorded from January 2014 to December 2018 out of which 205 were for acute exacerbation of asthma, making the overall prevalence rate of asthma related emergency room admission to be $2.9 \%$. The year 2015 recorded the highest prevalence of acute asthma admissions with a rate $4.8 \%$ (72 out of 1487), while the lowest rate of $1.7 \%$ (29 out of 1710 ) was seen in 2018 (Figure 1).

The 205 admissions were recorded among 183 patients, however 3 admission cases were excluded from the analysis due to incomplete records making the number analyzed to be 202 . The mean age of the patients was $6.1( \pm 4.2)$ yrs, their age ranged from 1 to 15 years with an $\mathrm{M}$ : F ratio of 1.97:1. Children aged 1 to 4 yrs (Table 1 ) were the highest in number $84(41.6 \%)$ while those $>12$ yrs were the least 22 (10.9\%). Among the 202 admissions only 28 (13.9\%) were already on follow up in the asthma clinic while $174(86.1 \%)$ were not on follow up in the asthma clinic. The maximum number of admissions per patient was three which occurred in 3 (3\%) patients.

Children on follow up in the clinic who were admitted into the emergency unit for asthma were more likely to have $\geq 2$ admissions over the study period (OR; 13, 95\% CI; 4.7, 37.9, P; 0.000001, Table 2).

The median length of hospital (LOH) stay was $24 \mathrm{hrs}$ while the mean LOH 


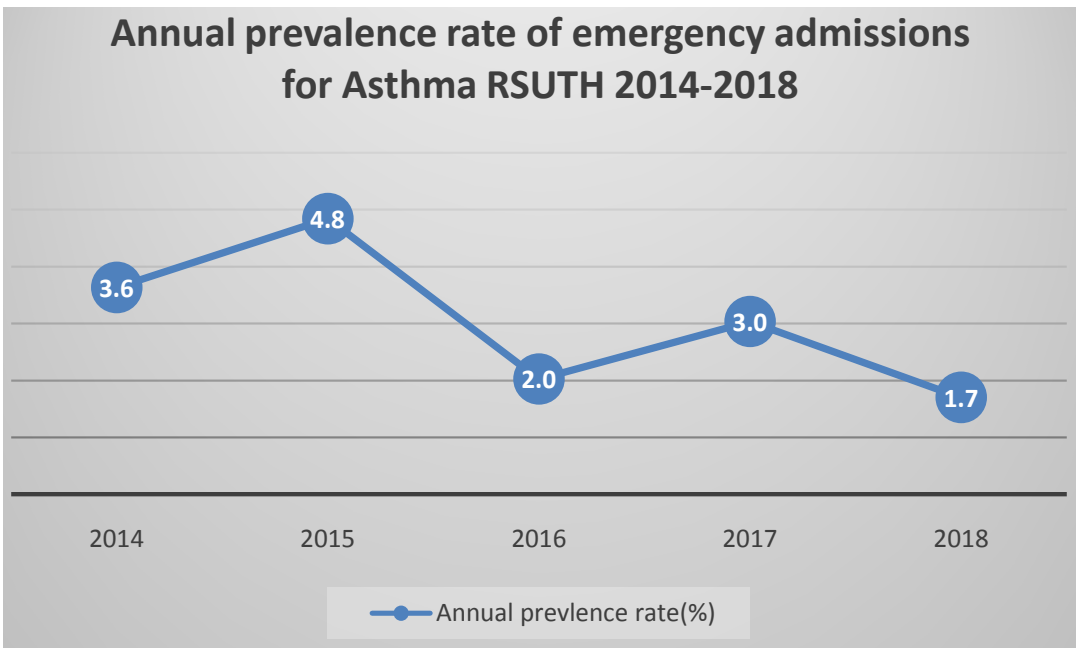

Figure 1. Prevalence rate per year of asthma admissions in emergency ward of RSUTH 2014-2018.

Table 1. Characteristics of children admitted for asthma into emergency department.

\begin{tabular}{|c|c|}
\hline Variable & All patients $(n=202)(\%)$ \\
\hline Age years (Median, $25^{\text {th }}, 75^{\text {th }}$ percentile) & $6(2.9)$ \\
\hline 1 to 4 & $84(41.6)$ \\
\hline$>4$ to 8 & $58(28.7)$ \\
\hline$>8$ to 12 & $38(18.8)$ \\
\hline$>12$ to 16 & $22(10.9)$ \\
\hline \multicolumn{2}{|l|}{ Gender } \\
\hline Female & $68(33.4)$ \\
\hline Male & $134(66.3)$ \\
\hline \multicolumn{2}{|l|}{ Asthma clinic follow up } \\
\hline Yes & $28(13.9)$ \\
\hline No & $174(86.1)$ \\
\hline \multicolumn{2}{|l|}{ Frequency of admission } \\
\hline 1 & $169(92)$ \\
\hline 2 & $9(5)$ \\
\hline 3 & $3(3)$ \\
\hline \multicolumn{2}{|l|}{ Duration of admission (Hrs) } \\
\hline $0-<24$ & $80(39.6)$ \\
\hline $24-<48$ & $98(48.5)$ \\
\hline $48-<72$ & $9(4.5)$ \\
\hline $72-<96$ & $10(5)$ \\
\hline$\geq 96$ & $5(2.5)$ \\
\hline
\end{tabular}

was $26 \pm 26$ Hrs. Most children 98 (48.5\%) were admitted for 24 hrs while only five children stayed $\geq 96 \mathrm{hrs}$. Children older than 11 yrs were more likely to be admitted for $>48$ hrs (Table 3: OR 4.18, 95\% CI; 1.67, 10.39, P; 0.003). 
Table 2. Patients admitted $\geq 2$ times 2014-2018.

\begin{tabular}{cccc}
\hline Follow up in clinic & Yes (\%) & OR (95\% CI) & P \\
\hline Yes & $11(39.3)$ & $13(4.7,37.9)$ & 0.000001 \\
No & $8(4.6)$ & & \\
Total & $19(9.4)$ & & \\
\hline
\end{tabular}

Table 3. Age and Mean length of hospital stay for acute exacerbation of asthma.

\begin{tabular}{cccc}
\hline Age $(\mathrm{yrs})$ & LOH $<48 \mathrm{hrs}(\%)$ & LOH $\geq 48 \mathrm{hrs}(\%)$ & Total \\
\hline$<11$ yrs & $152(91.6)$ & $14(8.4)$ & 166 \\
$\geq 11$ yrs & $26(72.2)$ & $10(7.7)$ & 36 \\
Total & $178(88.1)$ & $24(11.9)$ & $202(100)$ \\
\hline
\end{tabular}

Sig $=0.003$, OR $4.176,95 \%$ CI $1.67,10.39$.

Being an old patient on follow up in asthma clinic, the patients' gender or year of admission did not significantly affect the duration of admission (Table 4). No asthma related death was recorded in the emergency department.

Emergency department visits for asthma was more in the rainy season April-September 129 (63.9\%) with a peak in May when compared to the dry season October to march 73 (36.1\%). The lowest deep in admission rate during the dry season was recorded in December and January (Figure 2).

There is a significant variation in the seasonal pattern of emergency room asthma admission with age $(\mathrm{P}=0.018)$. Children $>3$ yrs have their highest admission rates in May with a gradual decline until August and October where they have lower surge in hospitalization rates. For younger children they experience two peaks in February and November (dry season) with the latter greater than the former. The months of May through to July (rainy season) seem to have a steady rate (Figure 3 ).

\section{Discussion}

We found that asthma exacerbation accounted for $2.9 \%$ of our emergency room visits, which is similar to $2.6 \%$ and $2.8 \%$ reported in Italy and USA [9] [10]. Although another Nigerian study conducted in Enugu found a higher prevalence rate of $6.5 \%$ [4] their study was done over a one year period as opposed to our study which was done over a 5 year period, as a result variation in annual prevalence rates which can be caused by other environmental factors could account for the observed difference. The year 2015 recorded the highest rate of emergency room visits and this could have been due to an improvement in health care given to asthma patients in the hospital by implementation of GINA guidelines for asthma management which could have led to better diagnosis [2] [11].

This study found that $41 \%$ of the children diagnosed with asthma were less than 4 yrs old. Younger children constitute a higher proportion of emergency room asthma visits. Donodi et al. found that children aged $<6$ yrs accounted for 


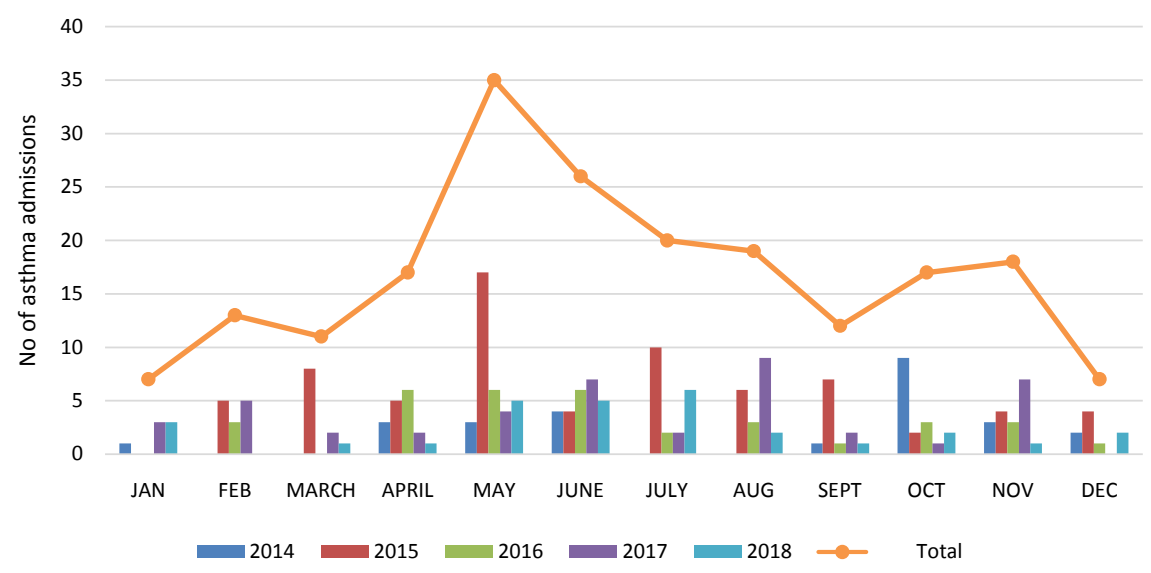

Figure 2. Seasonal pattern of acute asthma admissions 2014-2018.

\section{Saesonal variation of Acute asthma with Age}

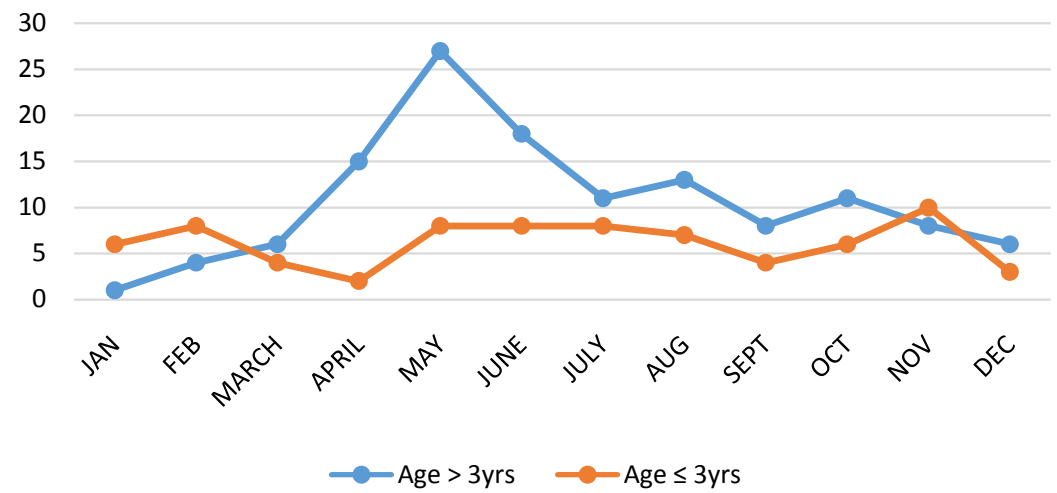

Figure 3. Seasonal variation of hospitalization for asthma exacerbation for children aged $\leq 3$ yrs and $>3$ yrs.

Table 4. Factors affecting length of hospital stay.

\begin{tabular}{cccc}
\hline & Mean LOH (Hrs) & SD & P \\
\hline Age (yrs) & & & \\
$1-4$ & 24.6 & \pm 24.12 & 0.004 \\
$>4-8$ & 22.1 & \pm 15.7 & \\
$>8-12$ & 44.1 & \pm 11.76 & \\
$>12-16$ & & \pm 52.2 & \\
Year & 28.15 & & \\
2014 & 29.67 & \pm 13.9 & 0.056 \\
2015 & 21.18 & \pm 32.78 & \\
2016 & 27.14 & \pm 15.92 & \\
2017 & 17.14 & \pm 29.28 & \\
2018 & & \pm 13.32 & \\
Follow up status & & & \\
No & 25.5 & \pm 22.2 & 0.6 \\
\hline
\end{tabular}




\begin{tabular}{cccc}
\hline Yes & 27.86 & \pm 42.3 & \\
Gender & & & \\
M & 26.5 & \pm 24.0 & 0.5 \\
F & 24.3 & \pm 29.0 & \\
\hline
\end{tabular}

$76.1 \%$ of paediatric emergency room visit in a single center study in Italy [9]. While in the USA, a 10 year national ambulatory medical care survey showed that the median age for paediatric asthma emergency room visit was 3.1 yrs [10]. Over years, the age at which asthma is being diagnosed in children has significantly reduced from 4.7 yrs in 1993 to 2.6 yrs in 2000 [12] the reason for this has been suggested to $b$ due to sensitivity of small airways to respiratory viruses like rhinovirus which could cause viral triggered wheeze as a result younger children are more likely to be misclassified as asthma [12]. Although this study did not exclude children younger than 2 years old as was done by Nath et al. [10]. The demonstration of Broncho constriction reversibility and reoccurrence of similar symptoms within 12 months could aid making the diagnosis of asthma in preschool aged children.

Predominantly first time presenters were seen in the emergency department during the study period and this is probably due to the hospital protocol in which all patients seen with asthma in the emergency department are referred to the paediatric respiratory clinic where they are assessed and given a self-management asthma action plan targeted at achieving control of their asthma symptoms. Having a self-management action plan for asthma reduces hospitalizations, emergency room visits, unscheduled clinic visits and improves asthma control which results in better quality of life for patients [13]. It is also not surprising that when patients who were already on follow up in the respiratory clinic were seen in the emergency department they were patients who had more severe symptoms that were relatively difficult to control as it is assumed that they already commenced a self-management at home according to their action plan which usually helps in treating mild asthma symptoms [14]. It is therefore more likely that these children came to the emergency room because they had a failed home treatment. The factors that could contribute to the relatively higher frequency of readmission seen in these patients could be either that they had more severe symptoms or were noncompliant to management plan, unfortunately this study was not able to identify these factors due to its limitations.

Length of hospital stay can be used to indirectly estimate resource consumption of treating an ailment and also evaluate the efficacy and quality of healthcare service being rendered within an institution. It can also help in planning and allocation of resources in health service delivery. In another Nigerian study [4] $90.4 \%$ of paediatric asthma cases who were treated in the emergency ward stayed $\leq 24$ hrs on admission which is similar to our center where the median LOH was 24 hrs. Similarity in localities and management protocol could have 
accounted for the findings as both centers made reference to use of GINA guidelines in Asthma management. In the United Kingdom however, a six year national review of hospital administrative data showed a median $\mathrm{LOH}$ of 2 days and a mean of 3 days [15]. Differences in Hospital admission and discharge policies could have affected the LOH besides the complexity of ailment and efficiency of health care.

Studies have shown that young children with asthma are more likely to be admitted and have a relatively higher health facility usage when compared to older children although, older children with acute asthma in the emergency department have poorer outcomes evidenced by longer LOH and higher mortality [16]. This is similar to our findings in which children $>11$ yrs were significantly more likely to be admitted for $>48$ hrs. The reason for poorer outcome among older children has been postulated to due to decreasing airway responsiveness to bronchodilators with age. In addition, under treatment of asthma symptoms in adolescents due to noncompliance to treatment and the social embarrassment they feel with use of inhalers could lead to them presenting with a more severe asthma in the emergency department [16] [17].

There was a steady decline in LOH stay from 2014 to 2018 with the exception of 2017 which recorded an increase to 2014 levels. The pattern seen in this trend could be because the hospital started a change in asthma management protocol from 2014 by creating a respiratory unit and implementing the GINA guideline for asthma management [11]. Over time, the improvement in outcomes of acute asthma management could be seen with shorter duration length of hospital stay. The hitch in the recorded progress seen in 2017 could be because the respiratory unit of the hospital witnessed a disruption in the follow up care usually rendered to asthma patients referred within the year in question. However, once the follow up care recommenced in 2018 the gradual decline in LOH stay for asthma patients in the emergency department continued.

We recorded no asthma death in the emergency department similar to findings in the Enugu study [4]. A 3 yr national survey of community hospital based emergency departments in the United States of America reported an asthma related mortality of 37 deaths per year in children at $0.003 \%$ [16]. This study was a large multicenter study across 4700 emergency departments which shows that a lot of the centers had no asthma related mortality although, the characteristics of the emergency departments with these mortality was not analyzed, one could still infer that, considering that the present study is a single center study in a tertiary center which renders specialist respiratory services, the absence of asthma related mortality in this study is not surprising. In a developing country like $\mathrm{Ni}$ geria with poor health care coverage, it is still possible that asthma related mortality occurs more within the community, outside the hospital setting due to poor access to health care, leading to unseen and undocumented mortalities.

This study shows that there are more asthma visits to the emergency department in rainy season than during dry season with a peak in the month of May. A similar finding has also been reported in another Nigerian study [4]. Asthma 
epidemics has been associated with high rainfall, increased humidity, decrease in environmental temperature and pressure [18]. Seasonal variation in allergen and viral exposures accounts for the epidemic pattern of asthma exacerbation seen in various geographic locations [19] [20]. During rainy season, there is an increase in pollen grain and mold spores leading to a rise in bio aerosols and respiratory allergens in susceptible individuals [18].

There is an age related difference in cyclic response to asthma causal factors which has led to a difference in cyclic pattern of asthma exacerbation seen in different age groups [21]. In temperate latitude of Northern hemisphere a September epidemic in asthma exacerbation has been described in school aged children which has been attributed to start of school with exposure to viral infections and allergy triggers [19]. In our study however there is a relative deep in September with asthma related emergency department visits although it seems to gradually rise in October. This could be because of a difference in academic calendar in western countries and Nigeria in which the academic session's starts mid-September as opposed to early September and late August in the UK and USA respectively.

In this study, children aged $<4$ yr old had a different pattern with two peaks in February and November and a plateau in most months of the rainy season. In preschool aged children asthma exacerbation is mostly triggered by respiratory infections while in older children it's by allergens and climatic changes [9].

\section{Conclusions}

Acute asthma is a common cause of emergency department admission in our hospital. The median length of hospital stay is $24 \mathrm{hrs}$. Older children are more likely to stay $>48$ hrs. Emergency department visits for asthma are highest during rainy season which is from April to September however, the seasonal pattern for asthma exacerbation in children varies with age.

The clinical importance of this information in asthma management is that pre-seasonal modifications can be made to treatment plans in order to improve asthma control and quality of life of these patients.

\section{Limitations of the Study}

This was a retrospective study and as a result it had some limitations. The fact that the asthma severity was not classified for these patients as part of the hospital admitting protocols made it impossible to access one major factor that could affect the length of hospital stay in these patients.

\section{Conflicts of Interest}

The authors declare no conflicts of interest regarding the publication of this paper.

\section{References}

[1] GEMA (2010) Asthma Exacerbation. The Journal of Investigational Allergology and 
Clinical Immunology, 20, 27-37.

[2] Global Initiative for Asthma (2018) Global Strategy for Asthma Management and Prevention. 15.

[3] Moorman, J.E., Akinbami, L.J., Baile, C.M., Zahran, H.S., King, M.E., Johnson, C.A. and Liu, X. (2012) National Surveillance of Asthma: United States, 2001-2010. Vital and Health Statistics Series, 32, 1-58.

[4] Edelu, J.O., Eze, J.N., Ayuk, A.C. and Oguonu, T. (2016) Prevalence and Pattern of Asthma Exacerbation in Children Seen at the University of Nigeria Teaching Hospital, Enugu. Nigerian Journal of Paediatrics, 43, 78. https://doi.org/10.4314/njp.v43i2.3

[5] Schauer, S.G., Cuenca, P.J., Johnson, J.J. and Ramirez, S. (2013) Management of Acute Asthma in the Emergency Department. Emergency Medicine Practice, 15, $1-28$.

[6] Won, Y.K., Hwang, T.H., Roh, E.J. and Chung, E.H. (2016) Seasonal Patterns of Asthma in Children and Adolescents Presenting at Emergency Departments in Korea. Allergy, Asthma \& Immunology Research, 8, 223-229.

https://doi.org/10.4168/aair.2016.8.3.223

[7] Teach, S.J., Gergen, P.J., Szefler, S.J., Mitchell, H.E., Calatroni, A., Wildfire, J., Bloomberg, G.R., Kercsmar, C.M., Liu, A.H., Makhija, M.M., Matsui, E., Morgan, W., O'Connor, G. and Busse, W.W. (2015) Seasonal Risk Factors for Asthma Exacerbations among Inner-City Children. Journal of Allergy and Clinical Immunol$o g y, 135,1465-73 . e 5$. https://doi.org/10.1016/j.jaci.2014.12.1942

[8] Silver, J.D., Sutherland, M.F., Johnston, F.H., Lampugnani, E.R., McCarthy, M.A., Jacobs, S.J., Pezza, A.B. and Newbigin, E.J. (2018) Seasonal Asthma in Melbourne, Australia, and Some Observations on the Occurrence of Thunderstorm Asthma and Its Predictability. PLoS ONE, 13, e0194929.

https://doi.org/10.1371/journal.pone.0194929

[9] Dondi, A., Calamelli, E., Piccinno, V., Ricci, G., Corsini, I., Biagi, C. and Lanari, M. (2017) Acute Asthma in the Pediatric Emergency Department: Infections Are the Main Triggers of Exacerbations. BioMed Research International, 2017, Article ID: 9687061. https://doi.org/10.1155/2017/9687061

[10] Nath, J.B. and Hsia, R.Y. (2015) Children's Emergency Department Use for Asthma, 2001-2010. Academic Pediatrics, 15, 225-230. https://doi.org/10.1016/j.acap.2014.10.011

[11] Onubogu, U. (2019) How to Implement Change in Asthma Management in a Developing Country. Open Journal of Respiratory Diseases, 9, 26-35. https://doi.org/10.4236/ojrd.2019.91003

[12] Radhakrishnan, D.K., Dell, S.D., Guttmann, A., Shariff, S.Z., Liu, K. and To, T. (2014) Trends in the Age of Diagnosis of Childhood Asthma. The Journal of Allergy and Clinical Immunology, 134, 1057-1062.e5. https://doi.org/10.1016/j.jaci.2014.05.012

[13] Gibson, P.G., Powell, H.F., Coughlan, J., Wilson, A.J., Abramson, M.F., Haywood, P.F., Bauman, A., Hensley, M.J. and Walters, E.H. (2003) Self-Management Education and Regular Practitioner Review for Adults with Asthma. The Cochrane Database of Systematic Reviews, 1, CD001117.

[14] Pollart, S.M., C.R. FAU and Elward, K.S. (2011) Management of Acute Asthma Exacerbations. American Family Physician, 84, 40-47.

[15] Soyiri, I.N., Reidpath, D.D. and Sarran, C. (2011) Asthma Length of Stay in Hospit- 
als in London 2001-2006: Demographic, Diagnostic and Temporal Factors. PLoS ONE, 6, e27184-e27184. https://doi.org/10.1371/journal.pone.0027184

[16] Tsai, C., Lee, W., Hanania, N.A. and Camargo Jr., C.A. (2012) Age-Related Differences in Clinical Outcomes for Acute Asthma in the United States, 2006-2008. Journal of Allergy and Clinical Immunology, 129, 1252-1258.e1. https://doi.org/10.1016/j.jaci.2012.01.061

[17] Trivedi, M. and Denton, E. (2019) Asthma in Children and Adults-What Are the Differences and What Can They Tell Us About Asthma? Frontiers in Pediatrics, 7, 256-256. https://doi.org/10.3389/fped.2019.00256

[18] Al-Rubaish, A. (2007) Thunderstorm-Associated Bronchial Asthma: A Forgotten But Very Present Epidemic. Journal of Family \& Community Medicine, 14, 47-51.

[19] Pike, K.C., Akhbari, M., Kneale, D. and Harris, K.M. (2018) Interventions for Autumn Exacerbations of Asthma in Children. The Cochrane Database of Systematic Reviews, 3, CD012393-CD012393. https://doi.org/10.1002/14651858.CD012393.pub2

[20] Wisniewski, J.A., McLaughlin, A.P., Stenger, P.J., Patrie, J., Brown, M.A., El-Dahr, J., Platts-Mills, T., Byrd, N.J. and Heymann, P.W. (2016) A Comparison of Seasonal Trends in Asthma Exacerbations among Children from Geographic Regions with Different Climates. Allergy and Asthma Proceedings, 37, 475-481. https://doi.org/10.2500/aap.2016.37.3994

[21] Johnston, N.W. and Sears, M.R. (2006) Asthma Exacerbations Â. 1: Epidemiology. Thorax, 61, 722. https://doi.org/10.1136/thx.2005.045161 